\title{
Physiological Changes in Cardiovascular System during Normal Pregnancy: A Review
}

\author{
Madhuri Taranikanti ${ }^{1}$ \\ ${ }^{1}$ Department of Physiology, ESIC Medical College, Hyderabad, \\ Telangana, India
}

Indian J Cardiovasc Dis Women-WINCARS 2018;3:62-67

\begin{abstract}
Address for correspondence Madhuri Taranikanti, MD, Professor and Head of Department, Department of Physiology, ESIC Medical College, Sanathnagar, Hyderabad 500038, Telangana, India (e-mail: madhuri.taranikanti@gmail.com; dr.taranikanti.madhuri@esic.in).
\end{abstract}

\author{
Abstract \\ Keywords \\ - cardiac output \\ - cardiovascular \\ adaptations \\ - neuro humoral factors \\ - pregnancy
}

Pregnancy is a complex biological process associated with changes in physiologic functions of the body. Dramatic changes take place in the cardiovascular physiology leading to gradual adaptation of these changes by the body of the pregnant woman. Cardiac output increases during pregnancy to 30 to 50\% above the prepregnant levels. The increase in cardiac output occurs due to increase in stroke volume initially during gestation and later by increase in heart rate. These changes in cardiac output are attributed to either neurohumoral factors such as estrogen and progesterone or placental factors. Maternal body position affects cardiac output with highest in kneel-chest and left lateral positions. Along with these changes, variations in heart rate, blood pressure, and blood volume are observed following a specific pattern of change during pregnancy. Hence, it is necessary to understand the cardiovascular changes during pregnancy to interpret, predict, and diagnose any cardiac disease efficiently.

\section{Introduction}

The term pregnancy is derived from the Latin words premeaning before and -gnatus meaning birth. It is the period from the time of fertilization to birth. It is a complex biological process that utilizes several resources of the mother as a result leading to widespread effects on the body of the pregnant woman. Pregnancy is a special physiologic condition that enables study of various bodily adaptations in normal individuals. Immediately after conception, growth of the fetus occurs tremendously by each week with changes in several systems to cause adaptation of the maternal body to the growing fetus. ${ }^{1}$ Changes occur in anatomical and physiologic parameters to protect the mother and support the growing fetus only to return to the prepregnant levels after the birth of the baby. One of the systems that changes remarkably during pregnancy is the cardiovascular system. These changes are necessary for a successful pregnancy outcome. To meet the increased metabolic needs of the tissues of the mother and the increasing demands of the growing fetus, blood flow to various organs increases. Metabolic shifts serve largely to support fetal demands and maximize maternal efficiency. ${ }^{2-5}$ Increasing blood flow is kept intact by the uninterrupted cardiac contractions to provide the required nutrients and oxygen. Hence, the metabolic needs of the heart rise and depend on continuous energy supply. ${ }^{6}$ Observations by Lindhard in 1915 that cardiac output (CO) increases during pregnancy formed the basis for subsequent work in circulatory physiology in pregnant woman. Structural changes occur in the heart with lateral and upward shift of cardiac apex to fourth intercostal space. Increased volume and shift of the heart provide more dullness over precordial region. Such alterations often lead to presence of systolic flow-type murmur commonly seen in pregnancy. Risk assessment for estimation of maternal and offspring risk is necessary and may be done through prepregnancy counseling and stratified as per the principles of modified World Health Organization (WHO) classification of maternal cardiovascular risk.?

\section{Cardiovascular Physiology of the Heart}

\section{Cardiac Output during Pregnancy}

Dramatic changes occur in $\mathrm{CO}$ early during pregnancy, starting in the first trimester and reaching peak by fifth month of gestation and continuing till delivery. ${ }^{8}$ Literature suggests an 
increase of 30 to $35 \%$ in CO over and above the nonpregnant levels. An increase in CO was demonstrated as early as 1949, but the cause for the increase was not clearly established whether it was due to increase in contractility of the heart or due to increased stroke volume (SV) caused by increased end diastolic volume. ${ }^{9}$ It is also not clear as per literature the precise time of peaking of $\mathrm{CO}$ during gestation. However, studies have shown that $\mathrm{CO}$ shows a peak anytime between 25 and 30 weeks. ${ }^{10}$ Several studies have shown that it is necessary to maintain a stable $\mathrm{CO}$ from the second trimester of pregnancy, which is achieved by increase in heart rate (HR) and decrease in $\mathrm{SV}^{10-16}$ ( - Fig. 1). A steady CO is seen from 24 weeks of gestation with a small decrease closer to term. ${ }^{15}$ Increased CO during the last trimester has not been projected sufficiently as a variety of studies are available showing a decrease, no change, or an increase, and have been mostly attributed to subjective adaptations of the mother during pregnancy along with interference by anthropometric variables of the mother and positioning of the body. ${ }^{13,16-26}$ Studies have also shown that this increased $\mathrm{CO}$ is likely to be enhanced in subsequent pregnancies. ${ }^{27}$ The changes in $\mathrm{CO}$ are attributed to either neurohumoral factors such as estrogen and progesterone or placental factors. ${ }^{28}$ Placenta behaving as a functional arteriovenous (AV) fistula leads to an increase in maternal HR too. As early as eighth week of gestation, the CO rises by $20 \%$, the possible mechanism associated being peripheral vasodilatation. Factors mediating this vasodilatation are synthesis of nitric oxide by endothelium and prostaglandins, leading to a fall in systemic vascular resistance and further increase in $\mathrm{CO}$ to almost $40 \% .{ }^{16}$ An increase in SV and an increase in HR are the main contributors for this mechanism. Relaxin produced by corpus luteum is found to have an effect in reducing the total peripheral resistance, thereby increasing $\mathrm{CO}$ and systemic arterial compliance. ${ }^{28-30}$ Though the proportion of $\mathrm{CO}$ to various organs remains similar to the prepregnant levels in the first trimester, due to the absolute increase in $\mathrm{CO}$ with advancing pregnancy, blood flow to all organs such as the uterus, breasts, kidneys, skin, brain, and heart increases by $50 \%$. There is a combination of increased preload, increased contractility and reduced afterload due to fall in systemic vascular resistance, all contributing to increased CO to nearly $50 \%$, thereby increasing the efficiency of the heart. ${ }^{19}$ There is an increase in coronary blood flow as coronary arteries become sensitive to stress-induced vasodilation. Venous return increases dramatically during pregnancy. Mean circulatory pressure that is an important determinant of venous return increases during pregnancy and resistance to venous return decreases.

\section{Maternal Body Position and Cardiac Output}

Studies on normal pregnant women have shown the CO to be highest in knee-chest and left lateral positions and less in standing and supine positions. The fall in supine position is attributed to the compression of the enlarged uterus on the inferior vena cava reducing the venous return, sometimes completely occluding it toward term and is more common after 24 weeks of gestation and earlier in twin pregnancies. However, a small percentage of women only experience the symptoms associated with supine hypotension during pregnancy. Understanding the benefits of posture-related effects of blood pressure on the body would help if a pregnant woman suffers from cardiac arrest requiring successful resuscitation. ${ }^{20,21,31}$

\section{Heart Rate Variations during Pregnancy}

Heart rate is found to increase progressively till the end of pregnancy reaching its peak in the third trimester ( - Figs. 2, 3). About 25\% change in heart from the baseline values has been noted. ${ }^{25,27,32}$ There is an increase in sympathetic activity during pregnancy that explains the increase in $\mathrm{HR}^{32} \mathrm{~A}$ possible explanation for sympathetic overactivity is that it occurs as a compensatory mechanism to peripheral vasodilatation, increased secretion of estradiol-stimulating nitric oxide synthesis leading to $\beta$-adrenergic-mediated vasodilatation. ${ }^{33}$ The

\section{Comparison of Cardiac Output and Stroke volume during pregnancy}

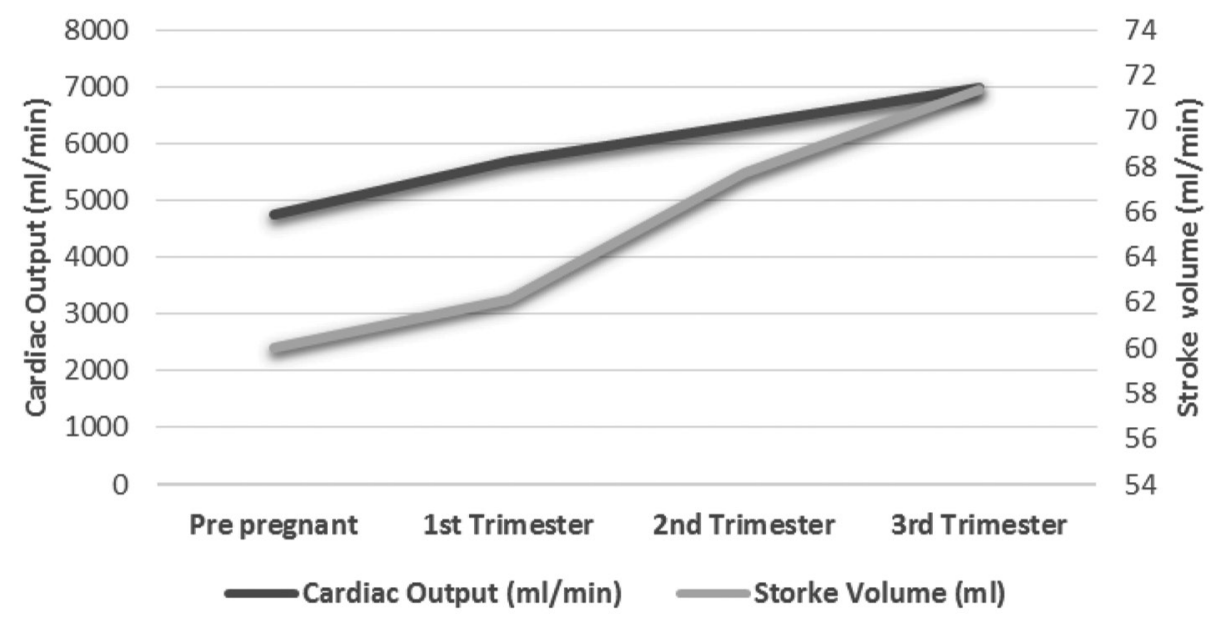

Fig. 1 Comparison of cardiac output and stroke volume in different trimesters of pregnancy. 


\section{Changes in heart rate with gestational age}

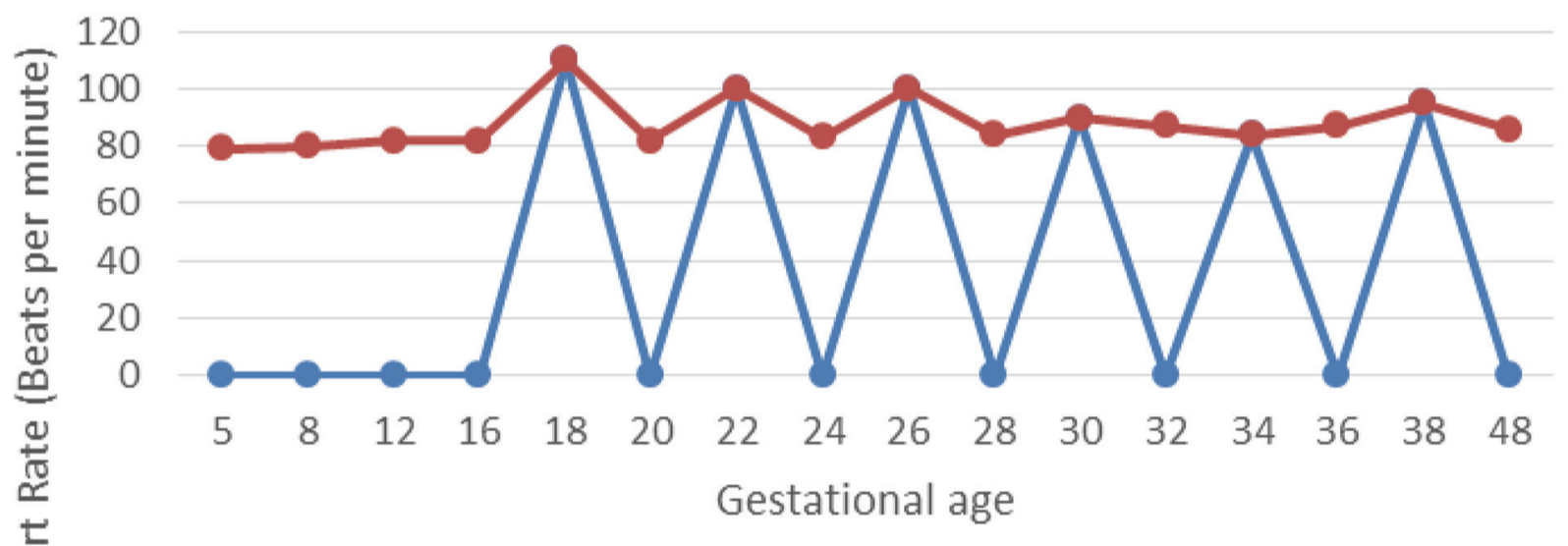

$\longrightarrow$ K.Laird-Meeter et al $\longrightarrow$ Hall ME et al

Fig. 2 Heart rate changes with gestational age.

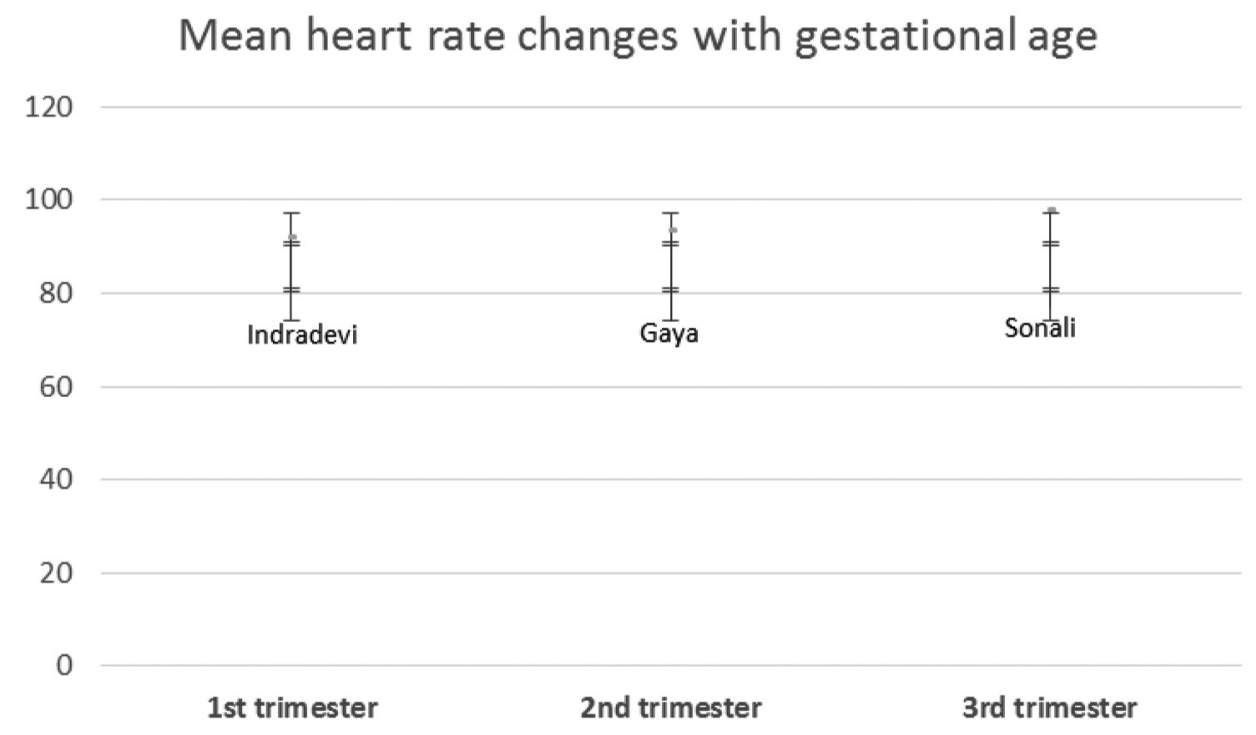

Fig. 3 Changes in mean heart rate with gestational age.

heart adjusts to higher fluid load by increasing the HR rather than increasing the end-diastolic volume, thereby increasing the CO. Echocardiography could not document any increase in end diastolic volume with increasing gestational age. ${ }^{34}$ However, there is an increase in left ventricular wall thickness and left ventricular mass during pregnancy, causing a concentric left ventricular remodeling due to additional circulatory needs during pregnancy. ${ }^{35}$ Commonly, a physiologic third heart sound and a cervical venous hum may be heard during pregnancy and need to be interpreted with caution being signs of systolic heart failure and patent ductus arteriosus, respectively.

\section{Changes in Blood Pressure during Pregnancy}

With fall in vascular resistance caused by progesteronemediated smooth muscle relaxation, blood pressure also falls up to midterm and then gradually rises. ${ }^{36,37}$ The combination of increased $\mathrm{CO}$ with fall in blood pressure is associated with reduced systemic vascular resistance. ${ }^{38,39}$ Overall vascular resistance is lower than prepregnant levels. Because nitric oxide is the main mediator for smooth muscle relaxation and fall in resistance, parallelly, there appears to be reduced response of vessels to vasoconstrictor agents as well. ${ }^{40}$ Overall, there is a fall in blood pressure by 5 to $10 \mathrm{~mm} \mathrm{Hg}$, with most of the fall occurring in the early part of pregnancy. ${ }^{39,41,42}$ 
Hence, the hemodynamic changes occurring during pregnancy should be compared with prepregnant values rather than early pregnancy period as many changes would have already taken place. The fall in blood pressure is seen in both systolic and diastolic blood pressures with the fall more prominent in diastolic blood pressure ( - Figs. $4, \mathbf{5}$ ). Some recent studies have shown that there is a progressive increase in blood pressure with gestation and that the increase is related to their body mass index. ${ }^{43}$ Obese and overweight women are seen to have higher blood pressure when compared with normal-weight women during early pregnancy, and this difference sustains throughout pregnancy. ${ }^{44}$ Variations in systolic and diastolic blood pressures and mean arterial pressure are observed in women across continents probably due to a subjective variation in other factors such as nutrition and anthropometric data. ${ }^{31,45-47}$

\section{Changes in Blood Volume during Pregnancy}

One of the hallmarks of pregnancy is a significant expansion of the blood volume, particularly in the first trimester and progressively later on. ${ }^{48-50} \mathrm{On}$ an average, the plasma volume increases by $40 \%$ along with an increase in erythropoiesis. Placental lactogen plays an important role in enhancing

\section{Blood pressure changes in normal pregnancy}

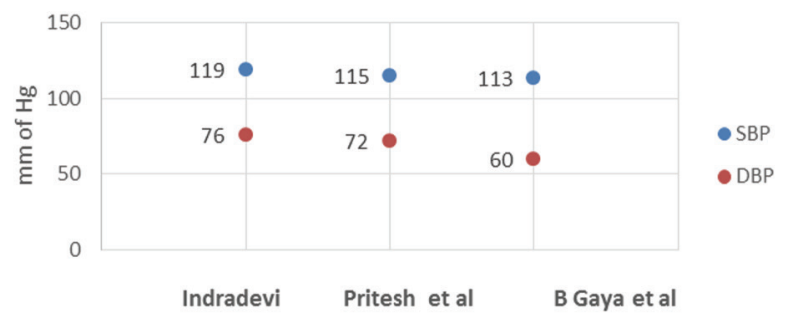

Fig. 4 Mean systolic (SBP) and diastolic blood pressures (DBP) during pregnancy. erythropoiesis by stimulating the production of erythropoietin. A condition of hemodilution occurs leading to physiologic anemia due to slight increase in plasma volume above the red cell mass. Though blood volume and SV increase, pulmonary capillary wedge pressure does not increase. Along with a fall in systemic vascular resistance, there is also a decline in the pulmonary vascular resistance. ${ }^{51}$ The combined effect of reduced colloid osmotic pressure with no significant increase in pulmonary capillary wedge pressure makes a pregnant woman susceptible to pulmonary edema. Hence, caution should be exercised while giving fluids to a pregnant woman to prevent any increase in preload that would precipitate pulmonary edema. ${ }^{52}$

\section{Changes in Electrocardiogram during Pregnancy}

Alteration in structure and function of the heart often leads to occurrence of systolic murmur during pregnancy. However, to label a pregnant woman with a diagnosis of heart disease, it is necessary to look for ECG changes that exceed normal variations during pregnancy. ${ }^{52}$ Changes occur in arrangement of chest organs, sympathohormonal changes, left ventricular dimension alteration based on hemodynamic requirements during pregnancy, all of which bring about changes in ECG. Left-axis deviation, occurrence of $\mathrm{Q}$-wave, and $\mathrm{T}$-wave abnormalities are common findings in ECG recordings during pregnancy. However, interpretation of these changes needs to be done with caution, though several times, these changes are seen as minor and temporary.

Understanding the physiologic changes during pregnancy is necessary to avoid any misinterpretation of these changes as pathologic processes. A systematic evaluation of hemodynamic changes during pregnancy is necessary. Any electrical changes in the heart should be evaluated cautiously due to large and subjective variations occurring during pregnancy. The cardiovascular changes are by and large temporary and reversible reverting back to the prepregnant levels within few weeks of delivery.

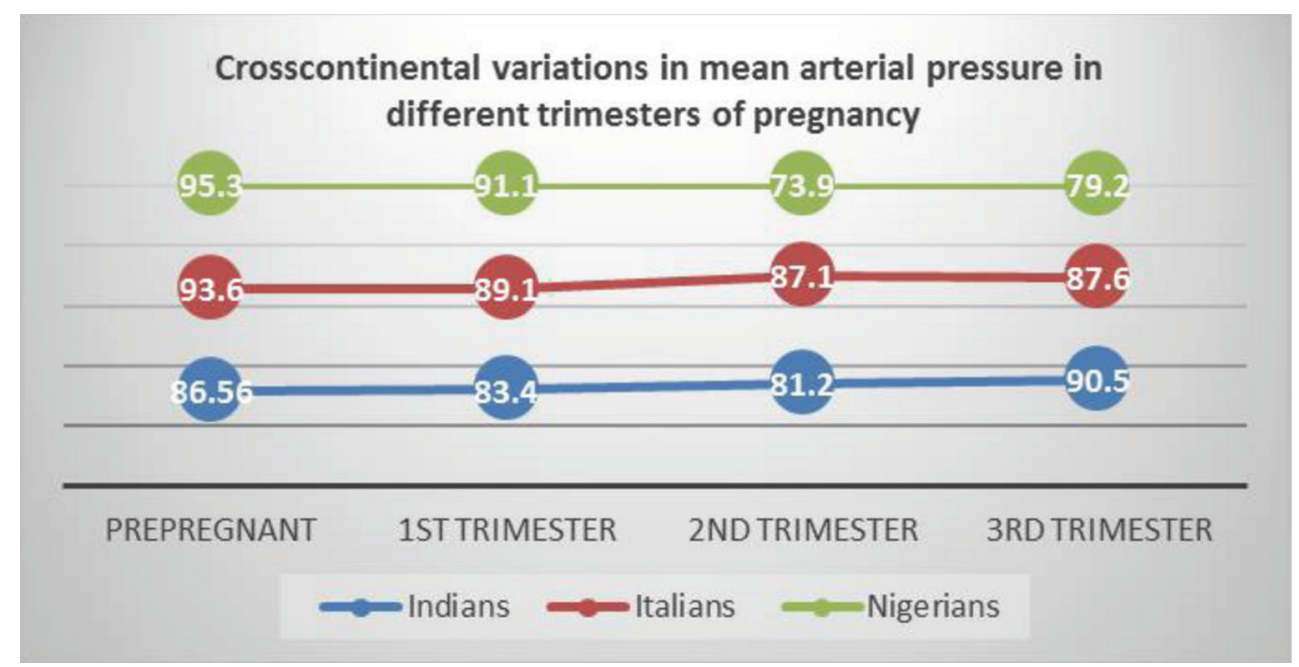

Fig. 5 Changes in mean arterial pressures with gestation. 


\section{References}

1 Lockitch G. Clinical biochemistry of pregnancy. Crit Rev Clin Lab Sci 1997;34(1):67-139

2 King JC. Physiology of pregnancy and nutrient metabolism. Am J Clin Nutr 2000;71(5, Suppl):1218S-1225S

3 King JC. Maternal obesity, metabolism, and pregnancy outcomes. Annu Rev Nutr 2006;26:271-291

4 Di Cianni G, Miccoli R, Volpe L, Lencioni C, Del Prato S. Intermediate metabolism in normal pregnancy and in gestational diabetes. Diabetes Metab Res Rev 2003;19(4):259-270

5 Lain KY, Catalano PM. Metabolic changes in pregnancy. Clin Obstet Gynecol 2007;50(4):938-948

6 Stanley WC, Recchia FA, Lopaschuk GD. Myocardial substrate metabolism in the normal and failing heart. Physiol Rev 2005;85(3):1093-1129

7 Regitz-Zagrosek V, Roos-Hesselink JW, Bauersachs J, et al; ESC Scientific Document Group. 2018 ESC guidelines for the management of cardiovascular diseases during pregnancy. Eur Heart J 2018;39(34):3165-3241

8 Hunter S, Robson SC. Adaptation of the maternal heart in pregnancy. Br Heart J 1992;68(6):540-543

9 Adeyeye VO, Balogun MO, Adebayo RA, et al. Echocardiographic assessment of cardiac changes during normal pregnancy among Nigerians. Clin Med Insights Cardiol 2016;10:157-162

10 Robson SC, Hunter S, Boys RJ, Dunlop W. Serial study of factors influencing changes in cardiac output during human pregnancy. Am J Physiol 1989;256(4 Pt 2):H1060-H1065

11 Volman MN, Rep A, Kadzinska I, et al. Haemodynamic changes in the second half of pregnancy: a longitudinal, noninvasive study with thoracic electrical bioimpedance. BJOG 2007;114(5):576-581

12 Akinwusi PO, Oboro VO, Adebayo RA, et al. Cardiovascular and electrocardiographic changes in Nigerians with a normal pregnancy. Cardiovasc J Afr 2011;22(2):71-75

13 Mabie WC, DiSessa TG, Crocker LG, Sibai BM, Arheart KL. A longitudinal study of cardiac output in normal human pregnancy. Am J Obstet Gynecol 1994;170(3):849-856

14 Thomsen JK, Fogh-Andersen N, Jaszczak P, Giese J. Atrial natriuretic peptide (ANP) decrease during normal pregnancy as related to hemodynamic changes and volume regulation. Acta Obstet Gynecol Scand 1993;72(2):103-110

15 Bosio PM, McKenna PJ, Conroy R, O'Herlihy C. Maternal central hemodynamics in hypertensive disorders of pregnancy. Obstet Gynecol 1999;94(6):978-984

16 van Oppen AC, Stigter RH, Bruinse HW. Cardiac output in normal pregnancy: a critical review. Obstet Gynecol 1996;87(2):310-318

17 Desai DK, Moodley J, Naidoo DP. Echocardiographic assessment of cardiovascular hemodynamics in normal pregnancy. Obstet Gynecol 2004;104(1):20-29

18 Sanghavi M, Rutherford JD. Cardiovascular physiology of pregnancy. Circulation 2014;130(12):1003-1008

19 Duvekot J, Cheriex EC, Pieters FA, Menheere PP, Peeters LH. Early pregnancy changes in hemodynamics and volume homeostasis are consecutive adjustments triggered by a primary fall in systemic vascular tone. Am J Obstet Gynecol 1993;169(6):1382-1392

20 Lees MM, Taylor SH, Scott DB, Kerr MG. A study of cardiac output at rest throughout pregnancy. J Obstet Gynaecol Br Commonw 1967;74(3):319-328

21 van Oppen AC, van der Tweel I, Alsbach GP, Heethaar RM, Bruinse HW. A longitudinal study of maternal hemodynamics during normal pregnancy. Obstet Gynecol 1996;88(1):40-46

22 Easterling TR, Benedetti TJ, Schmucker BC, Millard SP. Maternal hemodynamics in normal and preeclamptic pregnancies: a longitudinal study. Obstet Gynecol 1990;76(6):1061-1069
23 Myhrman P, Granerus G, Karlsson K, Lundgren Y. Cardiac output in normal pregnancy measured by impedance cardiography. Scand J Clin Lab Invest 1982;42(6):513-520

24 Hennessy TG, MacDonald D, Hennessy MS, et al. Serial changes in cardiac output during normal pregnancy: a Doppler ultrasound study. Eur J Obstet Gynecol Reprod Biol 1996;70(2):117-122

25 Atkins AF, Watt JM, Milan P, Davies P, Crawford JS. A longitudinal study of cardiovascular dynamic changes throughout pregnancy. Eur J Obstet Gynecol Reprod Biol 1981;12(4):215-224

26 Somani, SS, Sunandini, R, Somani, SG. Role of echocardiography for assessment of cardiovascular haemodynamics during pregnancy. IJRCOG 2016;5(1):84-89

27 Clapp JF III, Capeless E. Cardiovascular function before, during, and after the first and subsequent pregnancies. Am J Cardiol 1997;80(11):1469-1473

28 Fisher C, MacLean M, Morecroft I, et al. Is the pregnancy hormone relaxin also a vasodilator peptide secreted by the heart? Circulation 2002;106(3):292-295

29 Conrad KP, Novak J. Emerging role of relaxin in renal and cardiovascular function. Am J Physiol Regul Integr Comp Physiol 2004;287(2):R250-R261

30 Walters WA, Lim YL. Cardiovascular dynamics in women receiving oral contraceptive therapy. Lancet 1969;27626: 879-881

31 Del Bene R, Barletta G, Mello G, et al. Cardiovascular function in pregnancy: effects of posture. BJOG 2001;108(4):344-352

32 Mahendru AA, Everett TR, Wilkinson IB, Lees CC, McEniery $\mathrm{CM}$. A longitudinal study of maternal cardiovascular function from preconception to the postpartum period. J Hypertens 2014;32(4):849-856

33 Jarvis SS, Shibata S, Bivens TB, et al. Sympathetic activation during early pregnancy in humans. J Physiol 2012;590(15):3535-3543

34 Stein RA, Michielli D, Fox EL, Krasnow N. Continuous ventricular dimensions in man during supine exercise and recovery. An echocardiographic study. Am J Cardiol 1978;41(4):655-660

35 De Haas S, Ghossein-Doha C, Geerts L, van Kuijk SMJ, van Drongelen J, Spaanderman MEA. Cardiac remodeling in normotensive pregnancy and in pregnancy complicated by hypertension: systematic review and meta-analysis. Ultrasound Obstet Gynecol 2017;50(6):683-696

36 Moutquin JM, Rainville C, Giroux L, et al. A prospective study of blood pressure in pregnancy: prediction of preeclampsia. Am J Obstet Gynecol 1985;151(2):191-196

37 Christianson RE. Studies on blood pressure during pregnancy. I. Influence of parity and age. Am J Obstet Gynecol 1976;125(4):509-513

38 Williams JG, Rincon-Skinner T, Sun D, et al. Role of nitric oxide in the coupling of myocardial oxygen consumption and coronary vascular dynamics during pregnancy in the dog. Am J Physiol Heart Circ Physiol 2007;293(4):H2479-H2486

39 Poppas A, Shroff SG, Korcarz CE, et al. Serial assessment of the cardiovascular system in normal pregnancy. Role of arterial compliance and pulsatile arterial load. Circulation 1997;95(10):2407-2415

40 Gant NF, Daley GL, Chand S, Whalley PJ, MacDonald PC. A study of angiotensin II pressor response throughout primigravid pregnancy. J Clin Invest 1973;52(11):2682-2689

41 Rebelo F, Farias DR, Mendes RH, Schlüssel MM, Kac G. Blood pressure variation throughout pregnancy according to early gestational BMI: a Brazilian cohort. Arq Bras Cardiol 2015;104(4):284-291

42 Nama V, Antonios TF, Onwude J, Manyonda IT. Mid-trimester blood pressure drop in normal pregnancy: myth or reality? J Hypertens 2011;29(4):763-768 
43 Grindheim G, Estensen ME, Langesaeter E, Rosseland LA, Toska $\mathrm{K}$. Changes in blood pressure during healthy pregnancy: a longitudinal cohort study. J Hypertens 2012;30(2):342-350

44 Bodnar LM, Ness RB, Markovic N, Roberts JM. The risk of preeclampsia rises with increasing prepregnancy body mass index. Ann Epidemiol 2005;15(7):475-482

45 Gandhi PH, Mehta HB, Gokhale AV, Desai CB, Gokhale PA, Shah CJ. A study on cardiac autonomic modulation during pregnancy by non-invasive heart rate variability measurement. Int J Med Public Health 2014;4(4):441-445

46 Gaya B, Talatu G, Adelaiye A. Cardiopulmonary changes in pregnant women in Sabon-Gari local government area, of Kaduna state, Nigeria. Internet J Health. 2009;9(2):4

47 Gaillard R, Bakker R, Willemsen SP, Hofman A, Steegers EA, Jaddoe VW. Blood pressure tracking during pregnancy and the risk of gestational hypertensive disorders: the Generation $\mathrm{R}$ Study. Eur Heart J 2011;32(24):3088-3097
48 de Haas S, Ghossein-Doha C, van Kuijk SMJ, van Drongelen J, Spaanderman MEA. Physiological adaptation of maternal plasma volume during pregnancy: a systematic review and meta-analysis. Ultrasound Obstet Gynecol 2017;49(2):177-187

49 Chesley LC. Plasma and red cell volumes during pregnancy. Am J Obstet Gynecol 1972;112(3):440-450

50 Rodger M, Sheppard D, Gándara E, Tinmouth A. Haematological problems in obstetrics. Best Pract Res Clin Obstet Gynaecol 2015;29(5):671-684

51 Soma-Pillay P, Nelson-Piercy C, Tolppanen H, Mebazaa A. Physiological changes in pregnancy. Cardiovasc J Afr 2016;27(2):89-94

52 M S, S C, Brid SV. Electrocardiographic QRS axis, Q wave and T-wave changes in 2nd and 3rd trimester of normal pregnancy. J Clin Diagn Res 2014;8(9):BC17-BC21 